\title{
LAS HERRERÍAS DEL MONASTERIO DE SAN JULIÁN DE SAMOS SEGÚN LOS EXPEDIENTES DE DESAMORTIZACIÓN
}

\author{
ESTEFANÍA LÓPEZ SALAS \\ Universidade da Coruña \\ ORCID iD: https://orcid.org/0000-0002-2889-6465
}

Copyright: C 2020 CSIC. La edición electrónica de esta revista se distribuye bajo los términos de una licencia de uso y distribución Creative Commons Reconocimiento 4.0 Internacional (CC BY 4.0).

Cómo citar/Citation: Estefanía López SALAs, "Las herrerías del monasterio de San Julián de Samos según los expedientes de desamortización", Cuadernos de Estudios Gallegos, 67, núm. 133 (2020), págs. 193-227, https://doi.org/10.3989/ceg.2020.133.07 


\section{LAS HERRERÍAS DEL MONASTERIO DE SAN JULIÁN DE SAMOS SEGÚN LOS EXPEDIENTES DE DESAMORTIZACIÓN}

\section{RESUMEN}

Entre finales de 1835 y principios de 1836 se redactaron los llamados inventarios de las herrerías del monasterio de San Julián de Samos, dentro del proceso desamortizador en el que, de forma general, se vieron envueltas todas las casas religiosas españolas. En el presente artículo proponemos utilizar estos documentos como recurso de aproximación al estudio de dichas herrerías en el momento de producirse su secularización, con el objetivo final de dar a conocer una parte de su historia, recuperar valores hoy perdidos y, en definitiva, entender cómo eran y cómo estaban organizados los distintos espacios de lo que hoy es un patrimonio industrial monacal desaparecido o muy transformado.

Palabras Clave: San Julián de Samos, monasterio, herrerías, desamortización, inventarios, patrimonio industrial.

\section{AS FERRERÍAS DO MOSTEIRO DE SAN XULIÁN DE SAMOS SEGUNDO OS EXPEDIENTES DE DESAMORTIZACIÓN}

\section{RESUMO}

Entre finais de 1835 e comezos de 1836 redactáronse os chamados inventarios das ferrerías do mosteiro de San Xulián de Samos, dentro do proceso de desamortización no que, de forma xeral, se viron envoltas tódalas casas relixiosas españolas. No presente artigo propoñemos utilizar estes documentos como recurso de aproximación ao estudo de ditas ferrerías no momento de producirse a súa secularización, co obxectivo final de dar a coñecer unha parte da súa historia, recuperar valores hoxe perdidos e, en definitiva, entender como eran e como estaban organizados os distintos espazos do que hoxe é un patrimonio industrial monacal desaparecido ou moi transformado.

Palabras ClaVE: San Xulián de Samos, mosteiro, ferrerías, desamortización, inventarios, patrimonio industrial.

\section{THE BLACKSMITHIES OF THE MONASTERY OF SAN JULIÁN DE SAMOS ACCORDING TO EXPROPRIATION DOCUMENTS}

\section{ABSTRACT}

From the end of 1835 to the beginning of 1836 the inventories of the blacksmithies that belonged to the monastery of San Julián de Samos were written, within the expropriation process that affected all the religious houses in Spain. The aim of the present article is to use these documents as a tool to study the appearance that these blacksmithies had when the secularization took place. Our last goal is to show one part of their history, to recover some lost values and, in the end, to understand how this present but missing monastic industrial heritage was, and how it was organized in a certain moment of the past.

KEY wORDS: San Julián de Samos, monastery, blacksmithy, expropriation, inventories, industrial heritage. 

1 siglo XIX fue particularmente adverso para el monasterio de San Julián de Samos, situado en la provincia de Lugo, en lo que se refiere a pérdidas y daños en su extenso patrimonio mueble e inmueble, tal y como ocurrió en muchas otras casas religiosas españolas. La exclaustración de 1820 marcó el inicio de ese proceso que, aunque paralizado en 1823, se acabó proclamando como definitivo a raíz de las leyes desamortizadoras de la década de 1830. La comunidad de monjes fue expulsada del monasterio y éste, junto a todas sus propiedades, pasó a manos del Estado quien, en la mayor parte de los casos, procedió a su venta a través de subastas públicas. Esto condujo a una dispersión del patrimonio monacal samonense que ha marcado claramente su evolución hasta nuestros días.

Pero antes de proceder a la venta, el primer paso dado por el Estado con los bienes desamortizados fue la realización de los llamados inventarios, unos documentos escritos en los que se relacionan todos los elementos que formaban parte de cada propiedad en el momento de la ejecución del mismo. Estos datos eran recogidos por el personal tasador, enviado por el comisionado de Amortización de cada Provincia, a través de inspecciones in situ. Por tanto, la información que contienen los convierte en herramientas únicas para conocer cómo eran los diferentes espacios monásticos en los años en los que se produjo la exclaustración. Y, en muchos casos, estos inventarios y otros documentos generados junto a ellos son la única fuente conservada con información sobre la realidad material decimonónica de un patrimonio hoy perdido o profundamente transformado.

En el presente artículo nos centramos en el estudio de la información que los inventarios realizados a raíz de la desamortización contienen sobre un tipo concreto de las múltiples propiedades que el monasterio de San Julián de Samos poseyó en el pasado, las llamadas herrerías (fig. 1). Documentalmente tenemos constancia de que la comunidad de monjes dirigía a principios del siglo XIX al menos seis herrerías situadas en diferentes lugares de las provincias de Lugo y Ourense: San Vicente, Rugando, Rodela, Gundriz, Santalla y Ferreira de Pallares. De todas ellas encontramos alguna noticia en diferentes expedientes de desamortización conservados en el Archivo Histórico Provincial de Lugo, particularmente interesantes en el caso 


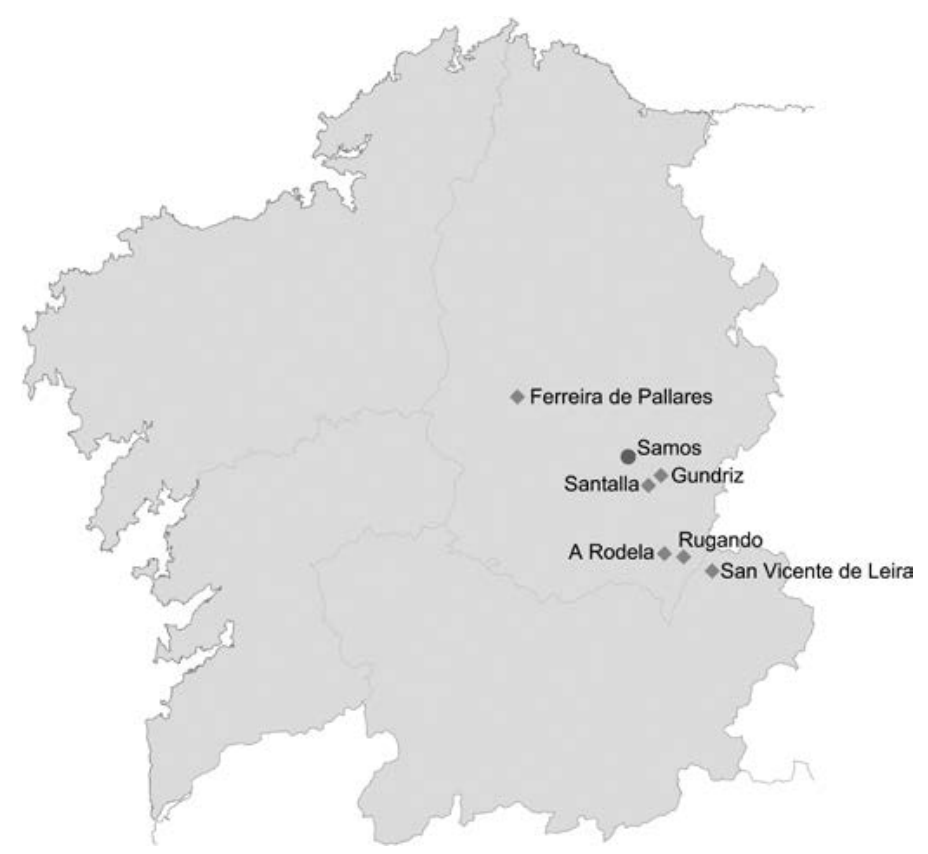

Fig. 1. Ubicación de las antiguas herrerías del monasterio de San Julián de Samos. Plano elaborado por la autora.

de los inventarios. A partir de estas fuentes trataremos de aproximarnos a la realidad histórica de una pequeña parte de un extenso patrimonio monacal.

\section{ESTADO DE LA CUESTIÓN}

Si nos retrotraemos al pasado, una de las primeras referencias al número total de herrerías pertenecientes al monasterio de San Julián de Samos la encontramos en el libro que, sobre la historia de esta casa, hizo el monje benedictino Plácido Arias Arias ${ }^{1}$. En él reflejó el nombre de aquellas, su ubicación y el año de su construcción, reconociendo ya a estas industrias como una de las fuentes principales de ingresos de la comunidad (figs. 2 y 3$)^{2}$.

\footnotetext{
1 Con anterioridad a Plácido Arias Arias los autores que estudiaron este tema sólo pudieron encontrar una referencia conjunta a las seis herrerías del monasterio de San Julián de Samos en un documento de Cornide Saavedra y Folgueira en el que da noticia de las herrerías localizadas en Galicia a fecha de su redacción, que nos es desconocida. Este documento se puede consultar íntegro en Clodio GonZÁLEz PÉREZ, A producción tradicional do ferro en Galicia: as grandes ferrerías da provincia de Lugo, Lugo, Deputación Provincial de Lugo, 1994, págs. 233-235.

2 Plácido Arias Arias, Historia del Real Monasterio de Samos, Santiago de Compostela, Imprenta, Lib. y Enc. Seminario Conciliar, 1950, págs. 245, 251, 255-256, 338-339.
} 


\begin{tabular}{c|c|c|c|c|c}
\hline Vena & Nombres & Parroquias & Dueños & Ríos & $\begin{array}{c}\text { Quints. de } \\
\text { producto }\end{array}$ \\
\hline $\begin{array}{c}\text { En su } \\
\text { inmediación }\end{array}$ & Pallares & S. Salvor. de Guntin & Samos & Ferreira & 650 \\
\hline Rocas & Gondriz & S. Cristovl. de Lozara & Samos & Lozara & 1000 \\
\hline Rocas & Santalla & S. Juan de Lozara & Samos & $\begin{array}{c}\text { La fuente de } \\
\text { su nombre }\end{array}$ & 700 \\
\hline Formigueiros & Rugando & S. Mamed de Fisteos & Samos & Soldón & 1500 \\
\hline Formigueiros & Rodela & $\begin{array}{c}\text { S. Salvador del } \\
\text { Hospital }\end{array}$ & Samos & Quiroga & 700 \\
\hline Formigueiros & $\begin{array}{c}\text { S. } \\
\text { Vicente }\end{array}$ & S. Vicente de Leire & Samos & S. Vicente & 1500 \\
\hline
\end{tabular}

Fig. 2. Extracto de la noticia dada por Cornide Saavedra y Folgueira sobre las herrerías de Galicia, con la selección de las pertenecientes al monasterio de San Julián de Samos: tomado de GonzÁLEz PÉrez, A producción tradicional..., págs. 233-235.

\begin{tabular}{c|c|c}
\hline Nombre & Ubicación & Año de construcción \\
\hline La de Gundriz & Lóuzara & 1555 \\
\hline La de Ferreira de Pallares & - & 1635 \\
\hline La de Santalla de Lózara & - & 1665 \\
\hline La de Quiroga & - & 1685 \\
\hline La de Rugando & Valdeorras & 1705 \\
\hline La de San Vicente de Leira & - & 1721 \\
\hline
\end{tabular}

Fig. 3. Relación de herrerías citadas por Plácido Arias Arias como pertenecientes al monasterio de San Julián de Samos: véase Arias Arias, Historia del Real Monasterio..., págs. $245,251,255-256,338-339$.

Estos datos fueron completados y ampliados por Maximino Arias Cuenllas en 1992, fecha de la publicación de su monografía sobre Samos, donde dedicó un capítulo completo al tema de las herrerías dirigidas por los monjes hasta su secularización en el siglo XIX ${ }^{3}$. En este segundo estudio, además de los datos recogidos anteriormente por Plácido Arias Arias, tenemos acceso a referencias más detalladas sobre su lugar de ubicación, los ríos de los que se servían cada una de ellas, los abades por cuyo mandato fueron construidas, el coste de algunas de sus obras o las rentas que el monasterio conseguía gracias a su producción (fig. 4). Asimismo, es destacable que la mayor parte de esta información fue recopilada por Maximino Arias Cuenllas gracias a la utilización de diferentes fuentes documentales históricas. Muchas de estas procedían del Archivo de la Congregación de San Benito de Valladolid en Silos, donde consultó los libros de actas de los capítulos generales, las actas de visita al monasterio de Samos y otra documen-

\footnotetext{
3 Maximino Arias Cuenllas, Historia del monasterio de San Julián de Samos, Samos, Monasterio de Samos; Diputación Provincial de Lugo, 1992, págs. 285-292.
} 
tación varia. Además, recopiló datos gracias a los pocos libros de estados del monasterio de Samos que, de finales del siglo XVIII, han llegado hasta nuestros días y, sobre todo, de la lectura del Catastro del Marqués de la Ensenada de 1753 correspondiente a las parroquias donde estas herrerías están ubicadas. En último lugar, este autor hizo referencia al destino de cada una de estas propiedades monásticas tras la exclaustración y a su estado de conservación en el momento del desarrollo de su investigación.

En el año que vio la luz la admirable historia sobre el monasterio de San Julián de Samos de Maximino Arias Cuenllas, otro estudioso, Clodio González Pérez, estaba dedicando su tiempo a la elaboración de la que puede ser considerada como

\begin{tabular}{c|c|c|c|c|c|c|c}
\hline \multirow{2}{*}{ Nombre } & $\begin{array}{c}\text { Abadiato } \\
\text { durante el } \\
\text { que se } \\
\text { construyó }\end{array}$ & $\begin{array}{c}\text { Catastro de Ensenada } \\
\text { (1753) } \\
\text { Producción/beneficios }\end{array}$ & \multicolumn{4}{|c}{$\begin{array}{c}\text { Libros de estados, } \\
\text { beneficios en reales }\end{array}$} \\
\cline { 3 - 9 } quint./año & reales & $\mathbf{1 7 7 7 - 8 1}$ & $\mathbf{1 7 8 1 - 8 5}$ & $\mathbf{1 8 1 4 - 1 8}$ & $\mathbf{1 8 1 8 - 2 4}$ \\
\hline Gundriz & $\begin{array}{c}\text { Francisco de } \\
\text { Parada }\end{array}$ & - & 11000 & 35000 & 19600 & 20000 & 14357 \\
\hline Santalla & $\begin{array}{c}\text { Antonio } \\
\text { Maseda }\end{array}$ & - & 3400 & 28720 & 37500 & 29500 & 1600 \\
\hline $\begin{array}{c}\text { Ferreira } \\
\text { de }\end{array}$ & $\begin{array}{c}\text { Mauro de } \\
\text { Vallares }\end{array}$ & - & - & - & 11803 & 19170 & 9800 \\
\hline Rodela & José Laguna & 660 & - & 46000 & 36400 & 14000 & 13202 \\
\hline Rugando & $\begin{array}{c}\text { José de } \\
\text { Nóboa }\end{array}$ & 825 & - & 89000 & 96000 & 62000 & 20000 \\
\hline \multirow{2}{*}{$\begin{array}{c}\text { S. Vicente } \\
\text { Sarmiento de }\end{array}$} & 1500 & - & 90480 & 108500 & 47000 & 31000 \\
\hline
\end{tabular}

\begin{tabular}{c|c|c}
\hline Nombre & Comprador & $\begin{array}{c}\text { Elementos conservados a finales del } \\
\text { siglo XX }\end{array}$ \\
\hline Gundriz & Antonio de Santamaría (Madrid) & $\begin{array}{c}\text { Casa vivienda del padre } \\
\text { administrador }\end{array}$ \\
\hline Santalla & Modesto Ma $\begin{array}{c}\text { Arango Trabadelo } \\
\text { (Lugo) }\end{array}$ & $\begin{array}{c}\text { Casa vivienda del padre } \\
\text { administrador }\end{array}$ \\
\hline $\begin{array}{c}\text { Ferreira de } \\
\text { Pallares }\end{array}$ & - & $\begin{array}{c}\text { Edificio de la herrería, sin } \\
\text { maquinaria. Convertida en serreria }\end{array}$ \\
\hline Rodela & - & Paredes de la fábrica, sin maquinaria \\
\hline Rugando & - & $\begin{array}{c}\text { Casa vivienda con su balconada y } \\
\text { capilla en ruinas, deshabitada }\end{array}$ \\
\hline S. Vicente & - & Muros de la casa vivienda, sin techo \\
\hline
\end{tabular}

Fig. 4. Arriba, algunos de los nuevos datos aportados por Maximino Arias Cuenllas sobre las herrerías del monasterio de Samos antes de la desamortización. Abajo, algunos de los datos aportados por Maximino Arias Cuenllas sobre las herrerías del monasterio de Samos después de la desamortización. Véase Arias Cuenllas, Historia del monasterio..., págs. 285-292. 
primera investigación rigurosa sobre el conjunto de herrerías que antiguamente funcionaban por toda la provincia de Lugo. Como resultado de esa labor, Clodio González Pérez publicó en 1993 un pequeño artículo en el que daba unas primeras pinceladas de lo que, un año después, sería su gran aportación a este tema de estudio $^{4}$. De 1994 es, por tanto, la primera monografía que ve la luz sobre la producción tradicional de hierro en la provincia de Lugo 5 .

A través de la obra de Clodio González Pérez se dio un paso adelante en el conocimiento de las herrerías que aquí nos ocupan. De hecho, este autor reconoce que los centros monásticos fueron los primeros empresarios del hierro en esta parte del territorio gallego ${ }^{6} \mathrm{y}$, aunque señala que todavía no existía en aquel momento un estudio detallado del papel que los monjes tuvieron en esta industria tradicional, también reconoce que "poucas deberon se-las empresas -en Galicia, que saibamos, ningunha-, que posuíron tantas fábrica como Samos"7. Por esa razón, a las herrerías de este monasterio les dedica un pequeño capítulo en el que hace referencia a cuestiones ya recogidas con anterioridad por Plácido Arias Arias y Maximino Arias Cuenllas, aunque si bien cita al primero de estos autores, no referencia al segundo, posiblemente porque todavía no conocía la monografía que este último ya había publicado mientras él hacía su investigación ${ }^{8}$.

Sin embargo, la parte más interesante del libro de Clodio González Pérez, para el estudio que ahora nos ocupa, es aquella en la que, como resultado de una labor de búsqueda de nuevas fuentes documentales y un intenso trabajo de campo desarrolló una ficha para cada una de las cuarenta y una antiguas herrerías lucenses por él halladas, entre las que figuran cinco de las seis que a principios del XIX eran dirigidas por el monasterio de Samos ${ }^{9}$. Cada ficha cuenta con tres apartados comunes (situación, historia y descripción de su estado a finales del siglo XX), que se completaron en algunos casos con planos de los edificios conservados y fotografías (fig. 5).

Para elaborar el apartado dedicado a la historia de cada una de esas propiedades, Clodio González Pérez se apoyó en la bibliografía entonces existente sobre el tema y en diferentes fuentes documentales por él localizadas. Entre estas últimas,

\footnotetext{
4 Clodio González PÉREz, "La producción tradicional de hierro en la provincia de Lugo: las ferrerías", Narria, 63-64 (1993), págs. 30-35.

5 González PÉRez, A producción tradicional....

6 González Pérez, A producción tradicional..., pág. 99.

7 GonzÁlez Pérez, A producción tradicional..., pág. 101.

8 GonzÁlez PÉREz, A producción tradicional..., págs. 101-103.

9 Figuran cinco de las seis, porque la herrería de San Vicente de Leira no se ubica en la provincia de Lugo, ámbito de su estudio, sino en la de Ourense. González Pérez, A producción tradicional..., págs. 169-171, 203-207, 215-218, 220-222.
} 


\begin{tabular}{c|c|c|c}
\hline Nombre & $\begin{array}{c}\text { Fecha de la } \\
\text { venta tras la } \\
\text { desamortización }\end{array}$ & $\begin{array}{c}\text { Comprador tras la } \\
\text { desamortización }\end{array}$ & Estado de conservación hacia 1992 \\
\hline Ferreira & 25 de mayo 1822 & $\begin{array}{c}\text { Marqués de } \\
\text { Valladares }\end{array}$ & $\begin{array}{c}\text { Bueno, casa habitada y convertida en } \\
\text { centro de una explotación ganadera }\end{array}$ \\
\hline $\begin{array}{c}\text { Rodela o } \\
\text { Queiroga }\end{array}$ & 1839 & - & $\begin{array}{c}\text { Casa abandonada con partes ya ruinosas, } \\
\text { al igual que establos, capilla y otras }\end{array}$ \\
\hline Rugando & 1839 & - & $\begin{array}{c}\text { Caserío con capilla abandonada con } \\
\text { partes desaparecidas }\end{array}$ \\
\hline Gundriz & 1839 & Antonio Santamarina & $\begin{array}{c}\text { Aceptable, habitada y sin grandes } \\
\text { reformas, la herrería convertida en } \\
\text { molino }\end{array}$ \\
\hline Santalla & $1820-23$ & - & $\begin{array}{c}\text { Casa del administrador en pie, pero muy } \\
\text { reformada, antigua capilla hoy iglesia } \\
\text { parroquias, herreria desaparecida }\end{array}$ \\
\hline
\end{tabular}

Fig. 5. Datos de las herrerías del monasterio de Samos ubicadas en la provincia de Lugo tras su desamortización, según GonzÁLEZ Pérez, A producción tradicional..., págs. 169-171, 203-207, 215-218, 220-222.

las únicas que podemos considerar como novedosas, por no haber sido previamente utilizadas por Plácido Arias Arias o Maximino Arias Cuenllas, son tres legajos procedentes del fondo de desamortización del Archivo Histórico Provincial de Lugo. La obra de Clodio González Pérez es el punto final de este breve recorrido historiográfico ${ }^{10}$.

\section{Metodología, OBJETIVOS Y FUENTES}

El trabajo que a continuación desarrollamos parte del conocimiento de todas estas obras previamente publicadas y se plantea como objetivo el aportar nuevos datos que nos permitan profundizar un poco más sobre el tema aquí objeto de investigación. Para ello, tal y como anunciamos en la introducción, nos vamos a apoyar en un conjunto de documentos que fueron generados durante la desamortización de las propiedades del monasterio de Samos en la tercera década del siglo XIX y que, hoy en día, se conservan en el Archivo Histórico Provincial de Lugo, en el llamado fondo de desamortización.

Hasta la fecha, tal y como el estado de la cuestión nos ha permitido constatar, sólo tres de esos documentos derivados del proceso secularizador fueron utilizados por Clodio González Pérez para estudiar las antiguas herrerías de este monasterio gallego. De dos de ellos este autor tomó datos puntuales que utilizó para elaborar

${ }^{10}$ Después de Clodio González Pérez, solo encontramos otra publicación que aporta algún dato más sobre las antiguas herrerías gallegas: Luis Guitián Rivera, "La destrucción histórica del bosque en Galicia", Semata Ciencias Sociais e Humanidades, 13 (2001), págs. 105-166. 
algunas partes de la historia de estas seis herrerías ${ }^{11}$. Del tercero, por el contrario, realizó una transcripción íntegra que incorporó al apéndice documental de su libro y que contiene la tasación del llamado priorato o herrería de Ferreira de Pallares, redactada el 9 de septiembre de 1821, con datos muy interesantes sobre la materialidad de ese espacio antes de su venta y cambio de propietarios ${ }^{12}$.

Durante el desarrollo de su tesis doctoral, la autora de este artículo llevó a cabo una revisión minuciosa de los documentos que sobre Samos y otros monasterios gallegos se custodian en distintos fondos del Archivo Histórico Provincial de Lugo ${ }^{13}$. El resultado de esa labor fue la localización de numerosos documentos, en su mayor parte inéditos, que le permitieron una aproximación más detallada a distintos aspectos todavía hoy desconocidos de la historia de esta casa monacal lucense. En este artículo concentraremos nuestra atención en mostrar nuevas noticias que, sobre las seis herrerías del monasterio de San Julián de Samos, hemos localizado en un total de tres legajos pertenecientes al ya citado fondo de desamortización ${ }^{14}$.

\section{LOS INVENTARIOS DE LAS HERRERÍAS DE SAMOS}

El 29 de julio de 1835 la Gaceta de Madrid publicaba el Real Decreto por el cual se ordenaba la supresión de la mayor parte de monasterios y conventos de religiosos ubicados en España ${ }^{15}$. Asimismo, el artículo 7 de ese mismo documento señalaba que todos "los bienes, rentas u otros efectos de cualquier clase que posean los monasterios y conventos que deban quedar suprimidos, se aplican (...) a la extinción de la deuda pública..."16, es decir, todas las propiedades monacales eran incautadas por el Estado.

Una vez publicado este Real Decreto, su contenido fue comunicado a los intendentes y comisionados de arbitrios de amortización de cada provincia, junto a una serie de disposiciones que estos últimos debían seguir para el cumplimiento adecuado de los objetivos de aquel ${ }^{17}$.

\footnotetext{
11 Se trata de los legajos 2 (4) y 10-2 (2) del fondo de desamortización del ArCHIVo HisTórico ProvinCIAL DE LUGo (en adelante AHPL).

12 Es el legajo 5 (1-2) del AHPL transcrito en GonzÁlez PÉrez, A producción tradicional..., págs. 236-238.

13 Estefanía López SALAS, San Julián de Samos-Lugo, estudio e interpretación del diseño monástico y su evolución [en línea], Tesis doctoral inédita, Universidade da Coruña, Escuela Técnica Superior de Arquitectura, 2015, disponible en: <http://ruc.udc.es/dspace/handle/2183/14723> [Consulta: 20/6/2017].

${ }_{14}$ Nos referimos a los legajos 181, 241 y 303, hoy correspondientes a las signaturas 18383,18444 y 18 506, respectivamente del fondo de desamortización del AHPL.

15 Gaceta de Madrid [en línea], núm. 211, págs. 841-842, disponible en: <www.boe.es/buscar/gazeta. php $>$ [Consulta: 25/6/2017].

${ }_{16}$ Gaceta de Madrid [en línea], núm. 211, pág. 842, disponible en: <www.boe.es/buscar/gazeta.php> [Consulta: 25/6/2017].

17 Así lo recoge el llamado Inventario I del monasterio de Samos y cuya transcripción ha sido reproduci-

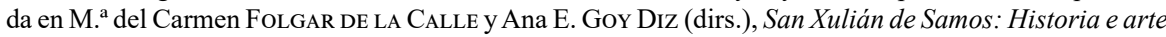


La primera disposición indicaba que el intendente era el responsable de hacer efectiva la supresión de las casas de religiosos ubicadas dentro de los términos de su provincia. Una vez efectuado este primer paso, debían comunicarlo al comisionado y al contador de arbitrios de amortización correspondientes para que estos tomasen posesión de todo lo que pertenecía a los monasterios suprimidos. El tercer punto del proceso era la formación de los inventarios de los bienes, rentas y otros efectos que el Real Decreto citaba en su artículo 7. Además, las disposiciones dadas especificaban a quién correspondía hacer los inventarios y qué datos debían ser recolectados:

$1^{\circ}$. Las fincas rústicas y urbanas con espresión de si se hallan arrendadas, a quién, en qué precio, y por cuánto tiempo, lo que adeuden los colonos o arrendatarios, dónde radican y las cargas de Justicia, así civiles como eclesiásticas. $2^{\circ}$. Los títulos de pertenencia de fincas, censos, foros, diezmos, prestaciones de todas clases, juros, efectos de villa, imposiciones en los fondos públicos y establecimientos mercantiles y particulares. $3^{\circ}$. Los bienes muebles y efectos semobientes, vales reales, créditos contra el estado y particulares, esistencias de dinero, frutos y demás que les correspondiese, escrituras y contratos de arriendos, los libros de asiento de cuenta y razón, y cuantos papeles o documentos se crean de utilidad al real servicio, los que se conserbarán en las contadurías de arbitrios, sin perjuicio de tomar los comisiones las noticias que tengan por más conducentes al mejor éxito de la comisión. $4^{\circ}$. Los archibos, bibliotecas, pinturas y demás enseres de utilidad a los institutos de ciencias y artes y $5^{\circ}$. Los monasterios y conbentos, sus yglesias, ornamentos y vasos sagrados, entendiendo uno y otro competentemente para su seguridad y destino subcesibo ${ }^{18}$.

Las personas escogidas para la redacción de los inventarios de los bienes pertenecientes al extinguido monasterio de Samos fueron el comisionado de arbitrios de amortización de la provincia de Lugo, Manuel María Vázquez Cadórniga; el juez del partido de Samos, Fernando de Bargas, y el alcalde de la misma villa, Manuel Losada y Pallín; en presencia del ex-abad del monasterio, fray Tomás Quiroga y otros testigos del lugar ${ }^{19}$.

nun mosteiro. Opus Monasticorum III, Santiago de Compostela, Xunta de Galicia, 2008, Apéndice documental [CD-ROM], Carpeta III, Inventario 1.

${ }^{18}$ Folgar de la Calle y Goy Diz (dirs.), San Xulián de Samos..., Apéndice documental [CD-ROM], Carpeta III, Inventario 1.

${ }^{19}$ Folgar de la Calle y Goy Diz (dirs.), San Xulián de Samos..., Apéndice documental [CD-ROM], Carpeta III, Inventario 1. 
El 4 de octubre de 1835 realizaron un primer inventario del monasterio que fue completado y ampliado unos meses después en un segundo y tercer inventarios, de 28 y 29 de abril de 1836, respectivamente ${ }^{20}$. En estos tres primeros documentos se relacionaron todas las propiedades rústicas y urbanas que los monjes poseían, tanto en las inmediaciones del monasterio, como en otros lugares más alejados, así como los bienes muebles hallados en el interior de las diferentes estancias de la casa religiosa.

Pero además de esa información, las disposiciones para el cumplimiento del Real Decreto indicaban que era necesario no sólo inventariar los bienes pertenecientes a los monasterios, sino también los de los prioratos anexos a ellos. Por esa razón, surgió la necesidad de redactar los inventarios correspondientes a las seis herrerías. En cada una de ellas vivía un monje llamado padre administrador, tal y como se señaló en el segundo inventario de abril de 1836, quien se ocupaba de su dirección y cuidado y, por esa razón, las herrerías podían ser consideradas como prioratos anexos al monasterio suprimido. De hecho, en una de las últimas visitas que los generales de la congregación de San Benito de Valladolid hicieron al monasterio de Samos antes de su exclaustración, en 1821, se establecen mandatos comunes para todos los prioratos y herrerías:

Ytem, encargamos al padre abad haga que en todos los prioratos y herrerías se pongan libros de visitas (...) en los que escriban los mandatos, y providencias, que se juzgasen convenientes para el mejor govierno, y adelantamiento de este monasterio en dichas dependencias (...) E igualmente mandamos que en la primera visita de dichos prioratos y herrerías se haga un exacto y puntual reconocimiento del estado en que se hallan sus casas, muebles, huertas, plantios, y todos sus terrenos, firmado por el padre abad o su comisión, y por los padres administradores de las referidas herrerías y prioratos, en un libro destinado para este efecto el cual reconocimiento mandamos se haga igualmente en los subcesivo al principio de todos los cuatrienios, firmándolo el padre administrador que acaba, y el que entra de nuevo, a fin de discernir por este medio quienes han conservado o perfectado, o al contrario, quienes han deteriorado las haciendas del monasterio, y poder en consecuencia apreciar el mérito de los unos, y reconvenir a los otros, y aún obligarlos a reparar

\footnotetext{
${ }^{20}$ El Inventario II y el Inventario III del monasterio de San Julián de Samos han sido transcritos de forma íntegra en Folgar de la Calle y Goy Diz (dirs.), San Xulián de Samos..., Apéndice documental [CDROM], Carpeta III, Inventarios 2 y 3.
} 
a su costa los daños o desperfectos que hayan causado por su culpa o indolencia ${ }^{21}$.

La primera noticia que hemos encontrado sobre las herrerías del monasterio de Samos en otros documentos derivados de la desamortización, distintos a los inventarios ya citados, hace referencia a la herrería de San Vicente, en el municipio de Vilamartín de Valdeorras (Ourense). Esta herrería aparece nombrada en una carta enviada por el juez gubernativo del distrito de Sobrado de Trives (Ourense), José Ventura Suárez y Puga, al contador de arbitrios de amortización de Lugo, con fecha 16 de noviembre de 1835 . En ella se hace saber al contador lucense que la responsabilidad de elaborar el inventario de la citada herrería es del juez de Sobrado de Trives, a quien el comisionado de arbitrios de amortización de la provincia de Ourense había nombrado para tal fin:

\begin{abstract}
Hallándome Delegado por el Señor Comisionado de Arbitrios de Amortización de la Provincia de Orense para la formación de inventarios de todos los Prioratos y Herrerías de este Partido que proceden de los Conventos suprimidos por los Reales Decretos de 25 de Julio, y 11 de Octubre inmediatos, creo conveniente el manifestar a V. S. que en el distrito de Baldeorras, se halla la Herrería de San Vicente procedente del Monasterio de Samos en esa Provincia y corresponde a la de Orense, y por consiguiente una de las de mi cargo adonde pienso dirigirme tan luego como me desahogue del trabajo en que estoy, entendiendo en igual clase echando mano para que me acompañe del Administrador de Rentas estancadas, $y$ en su defecto del Juez o Procurador Local caso que no aparezca un sujeto con nombramiento expreso de V. S. a cuyo efecto espero se servirá avisarme sin perder correo para que no padezcan retraso los sentimientos de S. M. en este particular $[. . .]^{22}$.
\end{abstract}

El 19 de diciembre de 1835, el mismo juez de Sobrado de Trives le envió una segunda carta al contador de arbitrios de la provincia de Lugo en la que le confirmaba que el inventario de la herrería de San Vicente ya estaba terminado y le hacía saber que, sin embargo, todavía no se había hecho lo mismo con la que dice

\footnotetext{
${ }^{21}$ El Libro de visitas, 1818-1834 del Archivo de San Paio Antealtares se puede consultar en FolgAR DE LA Calle y Goy Diz (dirs.), San Xulián de Samos..., Apéndice documental [CD-ROM], Carpeta I, Libros de acta de visita.

${ }^{22}$ Clero regular. Correspondencia con los encargados por la contaduría, para la formación de inventarios motivados por la supresión de los conventos, en AHPL, legajo 303, sign.: 18 506, sin foliar.
} 

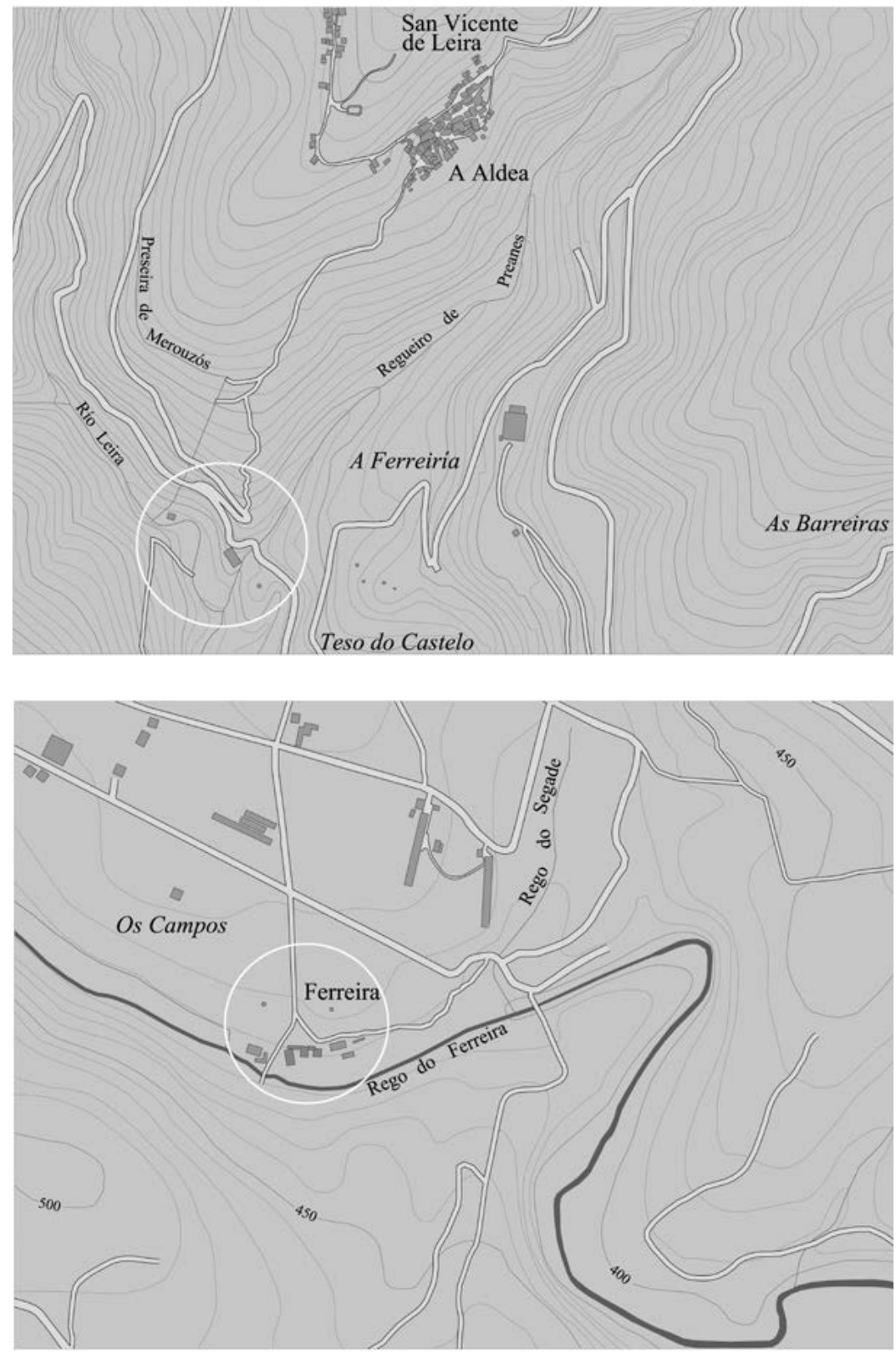

Fig. 6. Arriba, plano de la herrería de San Vicente de Leira. Abajo, plano cartográfico de la herrería de Ferreira de Pallares. Planos elaborados por la autora tomando como base el mapa topográfico nacional de España, a escala 1:25.000, en Ministerio DE FoMENTo, Instituto Geográfico Nacional (IGN) [en línea], disponible en: <http://www.ign.es/> [Consulta: 1/7/2017]. 
cercana herrería de Rugando, también procedente del monasterio de Samos, aunque ubicada dentro de los límites de la provincia de Lugo:

\begin{abstract}
Cumpliendo con el encargo que $V$. me hace en su oficio de 26 de Noviembre último, debo decirle que he practicado, y ultimado el inventario de la Herrería de San Vicente procedente del Monasterio de Samos según la Instrucción puesta por la Dirección General de Amortización; advirtiendo a $V$. que según estoy informado, aún no se practicó igual diligencia con la Herrería de Rugando procedente de dicho Monasterio, y se halla en estas inmediaciones, pero pertenece a esa Provincia de Lugo, cuya noticia deberá darle a ese Señor encargado Administrador caso que no la tenga $[\ldots]^{23}$.
\end{abstract}

En el mismo legajo del que forman parte las dos cartas anteriores también se halla otra referencia al priorato o herrería de Ferreira de Pallares. El 23 de diciembre de 1835 se dio orden al juez gubernativo de Ferreira de que junto a Manuel María Vázquez Cadórniga y Antonio Fernández, procedieran a la formación del referido inventario, de acuerdo a las disposiciones anteriormente citadas $^{24}$.

Aunque los tres documentos hasta aquí referenciados nos permiten confirmar que los inventarios de los bienes que formaban parte de las herrerías de San Vicente y de Ferreira de Pallares fueron realizados en el mes de diciembre de 1835, no hemos podido localizar la copia de los mismos en los fondos del Archivo Histórico Provincial de Lugo (fig. 6).

No acurre así, sin embargo, con las otras cuatro herrerías: Gundriz, Santalla, Rugando y Rodela. Sus correspondientes inventarios forman parte del legajo 241 del fondo de desamortización del archivo citado. Al análisis de cada uno de ellos vamos a dedicar los siguientes apartados.

\title{
LA HERRERÍA DE GUNDRIZ EN 1836
}

El inventario de la herrería de Gundriz, ubicada en la parroquia de San Cristovo de Lóuzara, en el actual ayuntamiento de Samos, fue realizado el 8 de enero de 1836 en presencia del comisionado y alcalde ordinario de esa jurisdicción, así como del ex-procurador del monasterio de Samos, Manuel Banante, y del ex-prior y administrador de la referida herrería, el benedictino Gregorio Jara.

\footnotetext{
${ }^{23}$ Clero regular. Correspondencia con los encargados..., en AHPL, legajo 303, sign.: 18 506, sin foliar. ${ }^{24}$ Clero regular. Correspondencia con los encargados..., en AHPL, legajo 303, sign.: 18 506, sin foliar. 
Siguiendo lo dispuesto en el Real Decreto correspondiente, el inventario se desarrolló en dos partes. En la primera de ellas, reconocieron las que podemos llamar fincas urbanas, es decir, todas y cada una de las edificaciones que constituían el conjunto en el momento de la redacción del inventario:

$1^{a}$ la casa de habitación, con sus oficinas, cocina, y más que contiene: con sus puertas, correspondientes cerraduras y llaves aunque toda ella bastante deteriorada, lo mismo que lo está el corredor que tiene a la parte del poniente: otra casa no contiene contraventanas ni cristales, la puerta que dice a la cocina; y mira a la caseta del horno es vieja como también la escalera que da entrada.

$2^{a}$ a otra cocina: la bodega del Yerro con dos puertas y dos llaves. $3^{a}$ La casa de Horno tiene su puerta y cerradura.

$4^{a}$ Hay otra caseta que sirve de pajar con dos puertas y sin cerraduras.

$5^{a}$ Y la Bodega del Vino con su puerta y llave.

$\sigma^{a}$ La casa de Herrería y Carbonera cubierta de madera y losa.

$7^{a}$ Un molino arriero corriente ${ }^{25}$.

La relación anterior nos permite saber el número total de construcciones que existían en la llamada Herrería de Gundriz, así como la función de cada una de ellas y algunos detalles relativos a su estado de conservación, entre otras cuestiones. A continuación del inventario de bienes urbanos, se dio cuenta de los llamados predios rústicos que completaban la propiedad, de la siguiente forma:

$8^{a}$ Una heredad de tres ferrados semiente junto a la Herrería, confina por el oriente con unas de Antonio Lago, mediodía con José y Antonio Marques por Occidente con Camino público, y por el norte con camino concejal que baja del lugar de Portela.

$9^{a}$ Un prado igualmente contiguo a dicha herrería, semiente ocho ferrados, confina por el oriente con Camino público mediodía con tierra de José Blanco, y por el Occidente con el Río de Lozara, y al norte con la huerta de la referida herrería.

$10^{a}$ Otro prado también contiguo a la herrería sembradura cuatro ferrados; demarca por el oriente con el Río de Lozara mediodía con Huerto de la herrería y por el occidente con Soto de Castaños

${ }^{25}$ 1836. Clero regular. Inventarios de bienes existentes en las casas herrerias de Gundriz, perteneciente al monasterio de Samos. Realizado según R.D. de 28 de julio de 1835, en AHPL, legajo 241, sign.: 18 444 , sin foliar. 
de Francisco María Pol, José López Carrete y otros vecinos de Gundriz por el norte con la zapacuña de la Herrería.

$11^{a}$ Una huerta, llevara en semiente un ferrado confina por el oriente con el Río de Lozara, mediodía con huerta de Antonio y José Marques vecinos de Gundriz por el occidente con terra de Antonio Lago, y por el norte con Prado de la Herrería.

$12^{a}$ Otra huerta, de un ferrado semiente confina por el oriente con Camino público mediodía con Prado de la herrería por el oriente con el Río Lozara ${ }^{26}$.

Con los datos anteriores termina el inventario de la herrería de Gundriz. A mayores de lo anterior, apoyándonos en otro legajo del fondo de desamortización, sabemos que esta propiedad fue vendida en 1839 por una cantidad de 155133 reales $^{27}$. Se sabe que siguió funcionando como herrería con sus nuevos compradores ${ }^{28}$, pero hacia las últimas décadas del siglo XIX, cesaría en su función original definitivamente ${ }^{29}$.

\section{LA HERRERÍA DE SANTALLA EN 1836}

El siguiente inventario realizado fue el de la herrería de Santalla, en la parroquia de San Xoán de Lóuzara (fig. 7), en el mismo ayuntamiento de Samos. Se llevó a cabo el día 21 de enero de $1836^{30}$. De nuevo, los encargados de redactarlo fueron el comisionado de arbitrios de amortización de la provincia, Manuel $\mathrm{M}^{\mathrm{a}}$ Vázquez Cadórniga, y el alcalde real y ordinario de la jurisdicción de Samos, Antonio María Losada, que contaron con la ayuda del ex-procurador del extinguido monasterio de Samos, Manuel Banante. Según se especificó en el inventario, el ex-procurador de Samos había arrendado la herrería de Santalla a Francisco Abad y Francisco Quintero en 1832.

Al igual que en el caso del inventario anterior, el recuento de bienes comenzó por las fincas urbanas. En este caso, sólo fueron relacionadas dos: la casa de

\footnotetext{
${ }^{26}$ 1836. Clero regular. Inventarios de bienes existentes en las casas herrerias de Gundriz,..., en AHPL, legajo 241, sign.: 18 444, sin foliar.

${ }^{27}$ Libro de registros de los Benedictinos de Samos y Lorenzana (1838...), en AHPL, legajo 10, sign.: 18 212 , sin foliar.

${ }^{28}$ GonzÁlez PÉRez, A producción tradicional..., 1994, pág. 217; GuITIÁN RIVERA, "La destrucción histórica del...”, pág. 141.

${ }^{29}$ Estadística Minera correspondiente al año de 1874 [en línea], Madrid, Dirección General de Estadística, Agricultura, Industria y Comercio, 1879, pág. 49, disponible en: <http://info.igme.es/estminera/default.aspx> [Consulta: 20/6/2017].

${ }^{30}$ 1836. Clero regular. Inventarios de bienes existentes en las casas herrerías de Santalla, en San Juan de Lózara, perteneciente al monasterio de Samos, según R.D. de 28 de julio de 1835, en AHPL, legajo 241, sign. 18 444, sin foliar.
} 

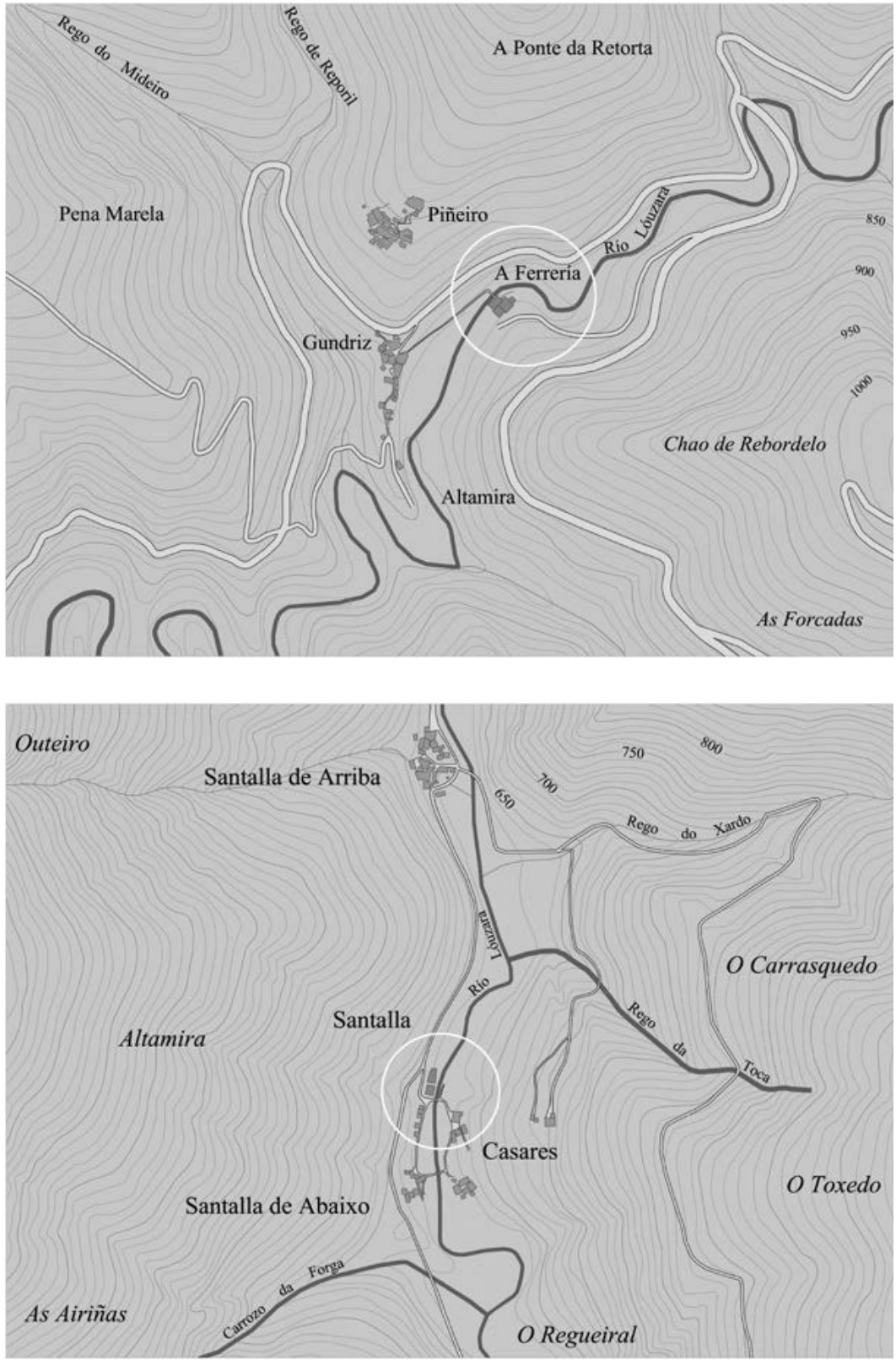

Fig. 7. Arriba, plano de la herrería de Gundriz. Abajo, plano cartográfico de la herrería de Santalla. Planos elaborados por la autora tomando como base el mapa topográfico nacional de España, a escala 1:25.000, en Ministerio de Fomento, Instituto Geográfico Nacional (IGN) [en línea], disponible en: <http://www.ign.es/> [Consulta: 1/7/2017]. 
habitación y la llamada fábrica. Sin embargo, a diferencia de lo visto en el inventario anterior, el grado de detalle alcanzando en las descripciones dadas de cada una de ellas fue mucho mayor, llegando incluso a inventariar los muebles existentes en el interior de la casa de habitación y las herramientas y otros aparatos que existían dentro de la fábrica o herrería. Por otra parte, aunque sólo se enumeraron dos construcciones, la lectura de los datos recogidos de cada una de ellas, nos permite deducir que existían al menos otras dos edificaciones más en la herrería de Santalla: una era la capilla y la otra un molino harinero:

$1^{a}[$... Jy dando principio hallaron la casa de habitación cubierta de losa y madera, sus fayados y pisos regulares con puerta de varias divisiones y puestas la de la cocina que dice al naciente se asegura además de su llave con un llavijón de hierro: tiene tres ventanas con sus vidrieras con algunos cristales, otra de puerta entera sin cristales, y todas ellas con sus cerraduras de pasador y clavijas; le dan luces otras cuatro ventanas con vega de Hierro, hay otras dos puertas que dan entrada al comedor por el naciente y norte la una sin cerradura sin llave, y la otras con dos pestillos de hierro: otra puerta en la escalera que sube de la herrería con dos clavijas y pestillo $=$ En los pisos bajos hay otras cuatro ventanas con rejas de hierro y madera: tiene tres cuadras separadas con sus puertas y clavijas de hierro la principal con cerradura: otra cuadra pequeña independiente de la casa principal con su puerta y clavija de hierro: las puertas de la bodega del vino con su cerradura llave y cerrojo = Las de la del hierro asegurada por adentro con trancas de madera; y toda dicha casa de un [vio] regular: y dentro de ella una alacena con varias divisiones asegurada con cuatro puertas y seis clavijas de hierro y una tiene su cerradura.

\section{Muebles}

Una mesa con buen uso con dos gaviotas, sus manillas, cerraduras y llaves $=$ un banco de respaldo más nuevo $=$ dos tarimas, la una con resguardo de catre: un taburete de madera bastante ordinario y usado = otra cama de torno $=$ en la siguiente habitación de la casa hay otras dos alacenas introducidas en las paredes con sus puertas la una con cerradura y llave = una escalera de mano $=$ dos asaderas de amasar pan de buen uso = un banco de cocina con su mesa de levante = otro banco de respaldo bastante usado, un estante o espetera con sus ganchos colgaduras de hierro = un andamio $=$ dos arcas, la una vieja y la otra a buen uso con cerradura y llave $=$ un estante con tres divisiones de tabla $=$ una medida de 
ferrado otra de medio, y otras de medio cuartillo = una paleta de hierro para la artesa $=$ dos cubetos parte de tres, y otro de seis, que ambos y dos contienen cuatro arcos de hierro cada uno = Hay una panera bastante usada dentro de dicha casa = Las balanzas de hierro con siete pesas de lo mismo, las cinco de a tres, cuatro, y seis libras, y las otras de a medio quintal otras balanzas de hierro para pesar la vena.

Junto a dicha casa hay una capilla la que se halla corriente con su puerta, cerradura y llave, contiene dentro de ella un misal y atril viejos $=$ dos manteles bastante usados = una alba y un amito sin trencillas viejo $=$ dos bolsas de corporales con uno de estos viejos una casulla de varios colores $=y$ su purificador $=$ dos candeleros de metal amarillo y una campanilla.

Fábrica y su herramienta

$2^{a}$ Hallan la fábrica con su cequillo viejo de peso cincuenta libras, betorre y más necesario; el árbol y rueda de mazar bien servibles y corrientes lo mismo que está el banzado, el mazo mango y yunque corrientes aunque aquel bastante viejo y remendado $=$ su cubo $y$ trompas servibles $=$ unas tenazas de repillar su peso cincuenta y seis libras $=$ otras dos de [cabear] de ciento noventa y cuatro $=$ dos [...] $=$ dos paletas $=$ las tenazas de partir las [Agoas] $=$ un torna carbón = y un martillo de la bena todo de peso de cien libras = la palanca mayor su peso setenta y cinco libras = dos palancas de levantar las [Agoas], una de fundir unas [burras] y la suara pesa todo ciento trece libras = dos tornos; una talladeira, dos picachos = un rodo, una pala, una marra, un maneiral, un podo de sacar la brasa y la talladeira de picar el hierro su peso ciento dieciocho libras, el árbol mayor tiene veinticuatro cellos $=$ un carretón $=$ una palanca del molino = una gramalleira = la fragua de manos con su armazón de madera y con sus seis cuero y tubera, y un yunque perteneciente a ella su peso cincuenta y seis libras = una tenaz llana $=y$ tres tuberas de cobre viejas de peso quince libras y media. Un molino arinero usual y corriente con su puerta, cerradura y llave ${ }^{3 l}$.

Posteriormente, se ocuparon de enumerar las fincas rústicas, un total de tres. De ellas recogieron los datos relativos a su superficie, uso y ubicación, pero sin alcanzar el grado de detalle de las descripciones de los predios urbanos:

\footnotetext{
${ }_{31}$ 1836. Clero regular. Inventarios de bienes existentes en las casas herrerías de Santalla..., en AHPL, legajo 241, sign. 18444 , sin foliar.
} 
$3^{a}$ Una huerta sobre la casa de ferrado y medio semiente, y parte de ella se halla a monte con algunos árboles frutales. $4^{a}$ Otra huerta a la parte de abajo de la misma casa su sembradura seis ferrados parte de ella a monte, con algunos montes y murada. $5^{a}$ Un prado secano tras del banzado de la fábrica de un ferrado en semiente que no produce más de pasto por su ínfima calidad ${ }^{32}$.

En último lugar, los redactores del inventario señalaron que todos los bienes anteriores se encontraban enajenados y que los había comprado "al tiempo de la Constitución, D. Ángel García de la Villa del Ferrol, por los que se pagan cuatrocientos ochenta reales de encabezado y ochenta por la vena del Señor Conde de Maceda" ${ }^{33}$. A este respecto, en otro legajo derivado del proceso desamortizador encontramos el dato de que la herrería de Santalla fuera vendida durante la primera exclaustración, entre 1820 y 1823, por un valor de 99000 reales $^{34}$. Los nuevos propietarios mantuvieron en funcionamiento la herrería de Santalla ${ }^{35}$ que, al igual que la de Gundriz, paró definitivamente de funcionar a finales del siglo XIX ${ }^{36}$.

\section{LA HERRERÍA DE RUGANDO EN 1836}

Al día siguiente de terminar el documento anterior, es decir, el 22 de enero de 1836, se procedió a realizar el inventario de la herrería de Rugando, ubicada en la parroquia de San Mamed de Fisteus, en el ayuntamiento de Quiroga ${ }^{37}$. Esta tarea fue llevada a cabo hasta el 26 de enero siguiente por el comisionado de arbitrios de amortización, el alcalde de la jurisdicción referida, el ex-procurador del monasterio y el administrador y ex-prior de la herrería, Vicente Rouson.

Comenzaron inventariando los tres bienes urbanos que formaban parte de la herrería de Rugando. Al igual que en el caso de la de Santalla, de cada una de esas construcciones se hizo una descripción muy detallada en la que se definía el uso de la mismas, los acabados de su interior, la compartimentación existente y el estado de puertas y carpinterías, entre otras cuestiones:

\footnotetext{
32 1836. Clero regular. Inventarios de bienes existentes en las casas herrerías de Santalla..., en AHPL, legajo 241, sign. 18 444, sin foliar.

${ }_{33}$ 1836. Clero regular. Inventarios de bienes existentes en las casas herrerías de Santalla..., en AHPL, legajo 241, sign. 18 444, sin foliar.

${ }^{34}$ Libro de registros de los Benedictinos de Samos y Lorenzana (1838...), en AHPL, legajo 10, sign. 18 212, sin foliar.

${ }^{35}$ GonzÁlez PÉRez, A producción tradicional..., pág. 222; GuITIÁN Rivera, "La destrucción histórica del...”, pág. 141.

${ }^{36}$ GonZÁlez PÉREz, A producción tradicional..., pág. 222.

37 1836. Clero regular. Inventarios de bienes existentes en las casas herrerías de Rugando, en la Jurisdicción y partido de Quiroga, perteneciente al monasterio de Samos, según R.D. de 28 de julio de 1835, en AHPL, legajo 241, sign. 18 444, sin foliar.
} 
$1{ }^{a}$ Primeramente de la casa habitación que se halla pisada, fayado, y cubierta de losa la que da entrada una puerta que está principal entre mediodía y norte que se asegura con cerradura y llave, pasada la cual hay una habitación a la izquierda con puerta cerradura y llave en la que se reconoce una tulla con su puerta asegurada con clavijas, y una ventana con reja de hierro, y a un lado otro cuarto con una ventana con su reja de hierro. Al frente dicha puerta principal hay una alcoba de tabla con puerta cerradura y llave, y otra habitación con otra tulla con su puerta cerradura y llave. A la derecha de la referida puerta principal, la bodega que se llama del Ferro con puerta cerradura y llave: tiene además otra y por la parte de afuera con su cerradura y llave y una ventana con reja de hierro, en ella hay una balanza para pesar el hierro con una pesa de cuatro libras, otra de siete, otras de arroba y media, otra de dos, y otra de cuatro. En seguida hay una cuadra pared en medio que tiene su entrada por la parte de afuera con su puerta que se asegura por adentro con una tranca de madera. A la subida de la escalera al piso alto hay una ventana con reja de hierro que la da luz. En la cima de dicha escalera se halla una sala que tiene una puerta rasgada y sale al balcón de madera que tiene dicha casa por la parte del mediodía asegurada con un clavijón de hierro. A un lado otra habitación con puerta, cerradura y llave; una ventana con clavija y reja de hierro. En seguida otra habitación que también tiene una puerta junto a la cocina con su cerradura y llave a la que la da luz dos ventanas con clavijas y rejas de hierro. A otro lado se halla la cocina con puerta cerradura y llave con otra hacia el patio con dos clavijones y cerrojos de hierro. A otro, otras puertas con cerradura, llave y picaporte que da entrada a otra habitación la que tiene su salida hacia el balcón por una puerta con dos clavijones de hierro visioneras; una ventana con clavija reja de hierro y vidriera. De esta habitación separa a otra con su puerta que se asegura con una clavija, tiene además otra hacia la cocina y la da luz una ventana con reja de hierro de esta se pasa a otra que tiene puerta con cerradura y llave que da luz una ventana con reja de hierro. Igualmente se pasa de esta a otras con puerta cerradura y llave y picaporte; tiene dos ventanas la una con vidriera y la otra con reja de hierro de ella se pasa a otra tiene puerta y picaporte, una ventana con reja de hierro y vidriera. De ella se pasa a la capilla y por una puerta tiene pasador y cerradura sin llave. Al norte de dicha casa hay un patio para el servicio de ella, y hacia el oriente la casa de horno con puerta y cerrojo de hiero. A un lado 
dos cuadras con sus puertas y clavijas. Dicho patio tiene una puerta con clavijas de hierro. A la parte de arriba del camino que pasa por delante de la casa de habitación hay cuatro casetas terrenas tres sirven de pagar y la otra para la fragua de manos tres de ellas con puerta, cerradura y llave.

$2^{a}$ Al mediodía de dicha Casa Río en medio hay la bodega con su puerta cerradura, llave, y una tranca de hierro, y además otra puerta con reja de madera cerrojo y cerradura sin llave.

$3^{a}$ A un lado del bancado de la Herrería hay un molino harinero corriente y moliente, con dos pisos para su servicio y una palanca de hierro pequeñ ${ }^{38}$.

A través de este inventario tenemos la oportunidad de conocer, con un alto grado de detalle, cómo era la casa principal de la herrería de Rugando en el momento de producirse la desamortización. Tenía planta baja y una altura. En la planta baja existían tres habitaciones, una bodega y una cuadra. La planta baja se comunicaba con la superior por una escalera que terminaba en una sala que se abría al exterior a través de un balcón. Además, en el piso alto existían ocho habitaciones, una cocina y una capilla. Exteriormente, la vivienda tenía un patio y una construcción anexa llamada casa del horno. Al otro lado del camino se hallaban cuatro casetas de planta baja y una quinta destinada a pajar. Los otros dos bienes inventariados, a mayores de la casa principal, fueron una bodega y un molino harinero. Finalizado el recuento de las construcciones, pasaron a relacionar los predios rústicos, un total de nueve, de la siguiente forma:

$1^{\circ}$ Una cortiña al nombramiento dos palleiros de medio ferrado semiente demarca por arriba con el camino que va a Parada y por abajo con prado de esta herrería.

$2^{\circ}$ Un prado contiguo a dicha cortiña con la que demarca por arriba, y por abajo con el río, contiene en sembradura ocho ferrados. $3^{\circ}$ Otro prado de medio ferrado semiente junto al referido de la partida anterior demarca por arriba con Camino que va a Parada por el Oriente con huerta de esta herrería, pared en medio.

$4^{\circ}$ Otro prado de un ferrado semiente que se halla al lado superior del que antecede camino en medio linda por el oriente con el arroyo de Caborco llamado del Infierno, al poniente con peñascos y por arriba con monte Común.

\footnotetext{
38 1836. Clero regular. Inventarios de bienes existentes en las casas herrerías de Rugando..., en AHPL, legajo 241, sign. 18444 , sin foliar.
} 
$5^{a}$ Una huerta de medio ferrado semiente, cerrada sobre sí con pared que se halla de la otra parte de dicho arroyo.

$6^{a}$ Una huerta con algunos árboles debajo del camino que viene de Parada a la herrería de un ferrado en sembradura, linda por arriba con dicho camino y por abajo con el río.

$7^{a}$ Otra huerta a la parte de arriba de la casa de habitación cerrada sobre sí con pared de medio ferrado en semiente.

$8^{a}$ Una cortiña de siete ferrados semiente del otro lado del río por cima de la tapacuña de la herrería demarca por arriba con el camino que va a Villarmiel y por abajo con el río.

$9^{\circ}$ Medio ferrado semiente sito al norte de la herrería con algunos árboles fructiferos y cepas cerrado sobre $\mathrm{si}^{39}$.

En este caso el inventario no terminó en los bienes rústicos, sino que consta de otros cuatro apartados más. El primero de ellos se titula "Rentas" y en él, se tomó nota de lo que el monasterio de Samos percibía como pago de los habitantes del lugar de Villarmiel. A continuación, figura la llamada relación de "Bienes muebles", donde se ocuparon de hacer constar por escrito los distintos utensilios, mobiliario, ropa y otros elementos que había en el interior de las diferentes construcciones en aquel momento:

Existen en dicha Casa de habitación para servicio de ella los muebles siguientes:

Cuatro mesas dos de ellas de buen uso y las otras deterioradas.

Cinco arcas viejas sin cerradura dos de ellas porte de diez fanegas una de seis y dos de a ocho.

Tres bancos de respaldo viejos.

Una balanza con una pesa de a cuarta, otra de media libra, una de dos, de cinco y otra de diez.

Una medida de aferrado.

Los estantes para libros.

Y en la casa de horno dos artesas para amasar pan y una pala de hierro.

Dentro de la capilla que se halla arrimada a la casa de habitación por donde tiene una entrada, y además otra por la parte de afuera con puerta cerrada y llave.

\footnotetext{
39 1836. Clero regular. Inventarios de bienes existentes en las casas herrerías de Rugando..., en AHPL, legajo 241, sign. 18444 , sin foliar.
} 
Su altar se compone de un cuadro del José, un crucifijo, sacras y evangelios viejos, y dos candeleros de metal tiene para su servicio un cáliz con su patena, y cucharilla de plata su peso todo dieciséis onzas, dos amitos viejos, dos Alvon usadas, un cingulo usado, tres casullas, encarnada, blanca y morada, esta de medio uso, y las otras dos bastante usadas con sus respectivos paños de cáliz y bolsas, tres corporales, cuatro purificadores, un atril, un misal bueno, un mantel de Altar, una mesa con un cajón, cerradura y llave para guardar los ornatos.

En la bodega cinco cubas grandes y pequeñas.

Una pipa nueva y cuatro cubetos más chicos.

La Casa de Herrería con carbonera, se hallan bien reparadas sin paredes, y los techos cubiertos de losa tiene dos puertas y la de la fábrica con cerradura y llave, en la parte superior de la carbonera hay una cuadra con puerta, cerradura y llave. El vanzado está bien servible, las ruedas de mazar y barquinera se hallan muy deterioradas. Los árboles arqueados de hierro de un regular servicio. Los fuelles surtidos de todo lo necesario y corrientes. El mazo y yunque buenos. El hogar de la fragua tiene las barras de hierro de costumbre, tubera y cequillo rodeada de aguas perdidas $^{40}$.

De la relación anterior, quedaron fuera los bienes muebles que había en el interior de la herrería o fábrica, es decir, las distintas herramientas de las que disponían para la manipulación del metal. Estas fueron señaladas en el siguiente apartado del inventario, titulado "Herramienta correspondiente a la fábrica":

Dos palancas de sacar las hagoas $=$ dos tornos de componer el yunque y mazo = unas tenazas burras = otras corvas $=$ dos patelas = una pequeña llana = otra corva un rodo de hierro = una suara $=$ un torna carbón $=$ dos palancas de fundir = dos marras y un marrote = un martillo de tazar la vena $=$ otro de partirla $=$ el camero $=$ dos picachos = y una pala para la vena $=$ cuyas herramientas pesan siete quintales $=$ dos barquites $=$ tres yunques $=$ cinco fenaces de toda clase $=$ cuatro martillos $=$ una tallada $=$ unos punteiros $=$ una $[\text { clabera }]^{41}$.

\footnotetext{
40 1836. Clero regular. Inventarios de bienes existentes en las casas herrerías de Rugando..., en AHPL, legajo 241, sign. 18444 , sin foliar.

${ }^{41}$ 1836. Clero regular. Inventarios de bienes existentes en las casas herrerías de Rugando..., en AHPL, legajo 241, sign. 18444 , sin foliar.
} 
A continuación, el inventario señala que la casa herrería de Rugando pagaba 200 reales cada año "al señor conde de Maceda por la vena que consume esta Herrería de su venera de Formigueiros" ${ }^{\text {"42 }}$. Asimismo, se manifestó que los ornatos existentes en la capilla de la herrería eran del monasterio de Samos y, como consecuencia, se hizo entrega de ellos al administrador de la herrería para que los devolviese a esa casa. En último lugar, se establece como necesaria la custodia de todos los bienes muebles e inmuebles relacionados en el inventario mientras no se decidía su nuevo uso. Para tal fin se nombró a tres vecinos del lugar de Parada, José de Soto, Juan Arias y Juan de Soto.

La lectura de este inventario, el tercero ejecutado en el mes de enero, nos permite comprobar que aunque estos documentos, derivados de la desamortización, tenían el mismo objetivo, no fueron siempre hechos con igual grado de detalle ni apartados.

En el caso de la herrería de Rugando, además del inventario, se conserva otro documento derivado del periodo de la desamortización con datos sobre su antigua configuración espacial. Se trata de la llamada "Relación que manifiesta las fincas rústicas y urbanas pertenecientes a la Herrería de Rugando dependiente del extinguido Monasterio de Samos, para que con presencia del pliego de condiciones adjunto se proceda a su arrendamiento en el presente año de 1837"43. Este documento fue redactado el 31 de diciembre de 1836, es decir, casi un año después del inventario, por José Vázquez Cañas y Enríquez. En él se relacionaron todos los bienes urbanos y rústicos ya contenidos en el inventario de principios de 1836, a excepción del primero, la llamada casa de habitación, utilizando las mismas descripciones.

La herrería de Rugando fue vendida en 1839 por una cantidad de 1120000 reales ${ }^{44}$. Los que la compraron la mantuvieron en uso hasta las primeras décadas del siglo $\mathrm{XX}^{45}$, aunque desde 1874 hay constancia documental de que no trabajaban en ella todo el $a_{n} \mathrm{o}^{46}$. Hoy en día funciona como casa de turismo rural.

\footnotetext{
42 1836. Clero regular. Inventarios de bienes existentes en las casas herrerías de Rugando..., en AHPL, legajo 241, sign. 18 444, sin foliar.

${ }^{43}$ Relación fincas rústicas y urbanas pertenecientes a la Herrería de Rugando, perteneciente al monasterio de Samos. 1836-37, en AHPL, legajo 181, sign. 18 383, sin foliar.

${ }^{44}$ Libro de registros de los Benedictinos de Samos y Lorenzana (1838...), en AHPL, legajo 10, sign. 18 212 , sin foliar.

45 GonzÁlez Pérez, A producción tradicional..., pág. 207.

${ }^{46}$ Estadística Minera correspondiente al año de 1874 [en línea], Madrid, Dirección General de Estadística, Agricultura, Industria y Comercio, 1879, pág. 49, disponible en: $<$ http://info.igme.es/estminera/default.aspx $>$ [Consulta: 20/6/2017]. Estadística Minera correspondiente al año de 1876 [en línea], Madrid, Dirección General de Estadística, Agricultura, Industria y Comercio, 1881, pág. 60, disponible en: $<$ http:// info.igme.es/estminera/default.aspx> [Consulta: 20/6/2017]. GonZÁlez PÉREZ, A producción tradicional..., págs. 206-207. Guitián Rivera, “La destrucción histórica del...”, pág. 142.
} 

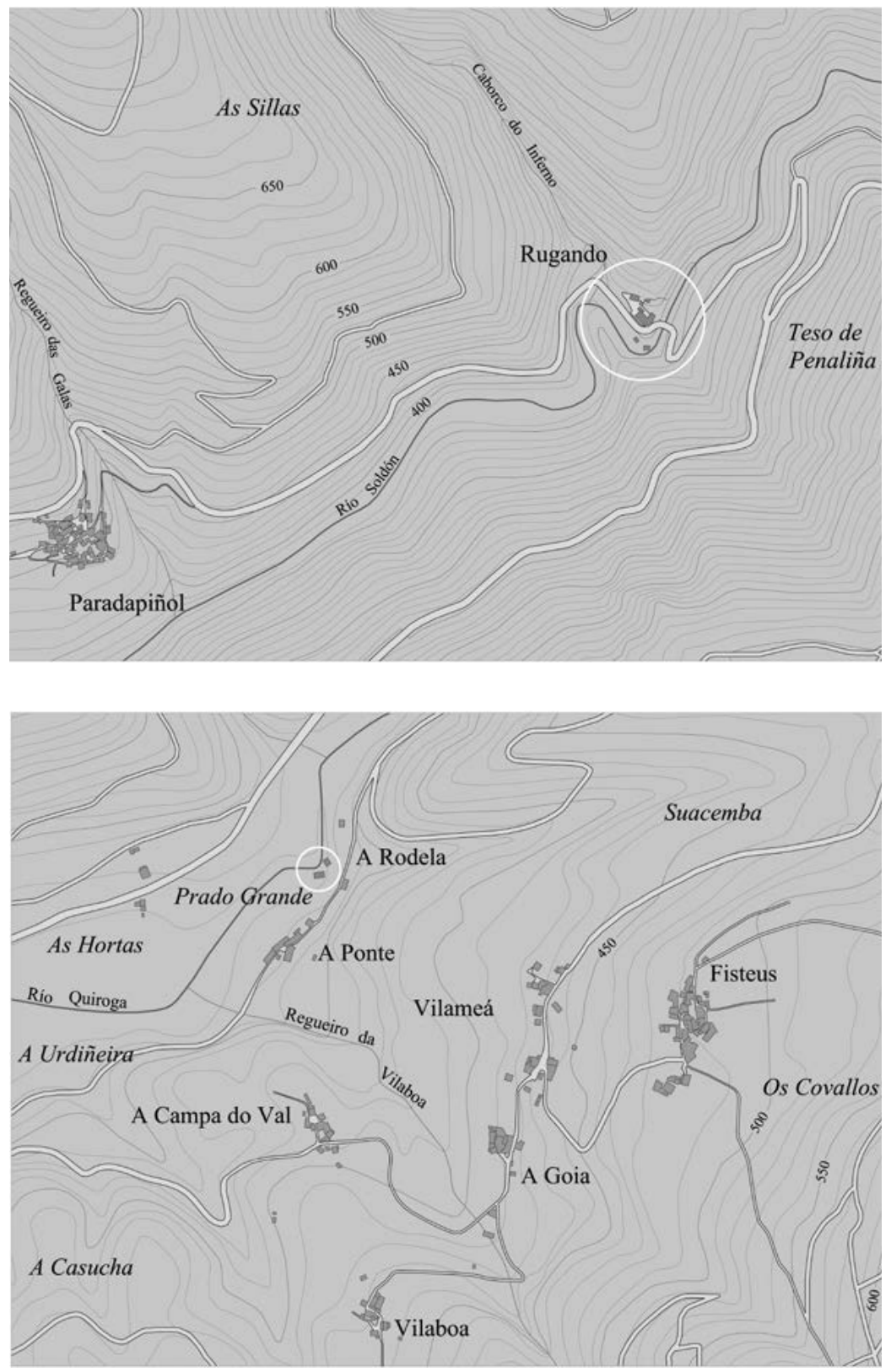

Fig. 8. Arriba, plano de la herrería de Rugando. Abajo, plano cartográfico de la herrería de A Rodela. Planos elaborados por la autora tomando como base el mapa topográfico nacional de España, a escala 1:25.000, en Ministerio De Fomento, Instituto Geográfico Nacional (IGN) [en línea], disponible en: <http://www.ign.es/> [Consulta: 1/7/2017]. 


\section{LA HERRERÍA DE A RODELA EN 1836}

La última herrería del extinguido monasterio de Samos en ser inventariada fue la llamada de A Rodela. Está ubicada en la parroquia de San Salvador del Hospital del municipio de Quiroga y no muy lejos de la herrería de Rugando (fig. 8). Su inventario se inició el día 23 de enero de 1836 y se terminó el 26 del mismo mes y, de nuevo, nos aporta la imagen escrita de una realidad espacial hoy transformada y parcialmente perdida ${ }^{47}$.

Se encargaron de hacer el inventario el comisionado de arbitrios de amortización de la provincia de Lugo, Manuel María Vázquez Cadórniga, el alcalde de Quiroga, Francisco María Polanco, el ex-procurador del extinguido monasterio de Samos, Manuel Banante, y el administrador de la herrería por arriendo que había hecho de ella, Miguel Somoza, vecino de Santa María de Tuimil, del ayuntamiento de Bóveda (Lugo).

A continuación, vamos a ver qué información nos aporta este inventario, el último en ser elaborado y también el más extenso de todos los hasta aquí analizados. En primer lugar, comenzaron definiendo los cuatro bienes urbanos de los que se componía la herrería, con las siguientes palabras:
$1^{a}$ La casa de habitación bien retejada tallada y pisada con buena madera, asegurada con cuatro puertas principales: la primera que dice a la parte del poniente que la da entrada con sus dos cerradu- ras y llaves; la segunda por la misma parte del poniente la que da entrada a la bodega del hierro la cual se halla atrancada por la parte de adentro por no hacerse uso de ella: tercera que dice a la parte de medio día da entrada a la bodega del vino cuya es para entrar a la ante bodega con reja de madera, cerradura de candado y llave; y la cuarta la que sale de la cocina al patio del horno con su clavija y clavijón y un cerrojo de hierro; dice a la parte del oriente. Tiene cuatro bahones de hierro con sus puertas de a dos hojas vargadas y aseguradas cada una con media [...], hay otras cuatro puertas balcón bien seguras con sus clavijones de hierro, trancas de madera, y antepecho con balaustres de hierro. Tiene otras varias ventanas de madera bien seguras con sus clavijas, $y$ entre ellas catorce grandes y pequeñas con su enrejado de hierro,

\footnotetext{
47 1836. Clero regular. Inventarios de bienes existentes en las casas herrerias de: Copia del inventario original, hecho de la casa herrería de Rodela, de todas las fincas, rentas y demás enseres que percibe D. Miguel Somoza, administrador, en virtud del arriendo que de todo realizó el comisionado especial Manuel María Cadórniga, según R. D. de 28 de Julio de 1835, perteneciente al monasterio de Benedictinos de Samos, en AHPL, legajo 241, sign. 18 444, sin foliar.
} 
en toda ella no hay más vidriera que una y cuatro maineles con sus cristales: todas sus oficinas se hallan con puertas y ventanas seguras, aquellas con sus cerraduras y llaves corrientes.

$2^{a}$ Otra casa terrena al mediodía de la principal que sirve de cuadra con pesebre, puerta, cerradura y llave.

$3^{a}$ Otra habitación que sirve de pajar y para guardar maderas, también con cerradura y llave, a cuyo frente o su tinglado existen dos tullas para curtir cueros.

$4^{a}$ Otra caseta por la parte del norte que sirve para la fragua de manos y un molino harinero usualy corriente ${ }^{48}$.

Seguidamente, se relacionaron un total de veintiuna fincas rústicas que, junto a las construcciones anteriores, constituían la herrería de A Rodela. La mayor parte de ellas eran sotos y, en menor medida, había prados, "cortiñas" y heredades, entre otras:

$1^{a}$ Una cortiña nombrada de la Puerta, de siete ferrados en sembradura poco más o menos, demarca por arriba con heredad de D. José María de Prado, por abajo camino público y poniente en más heredad del mismo D. José.

$2^{a}$ El soto que llaman "Sotelo" de cinco ferrados en semiente demarca por arriba con el camino que va para la Herrería de Paleiras y por abajo con el río Quiroga, poniente con el arroyo de Sabugas, y por el otro lado con el soto de los herederos de Juan Rubio de San Cristóbal.

$3^{a}$ El soto y prado de la Rivera que todo llevará diez ferrados en semiente, demarca por arriba con el monte y por abajo con el Río Quiroga, oriente, y poniente con el arroyo de Malcatán.

$4^{a}$ El soto de Redinin, de seis ferrados, en semiente, demarca por arriba con el monte de [...], por abajo con el río Quiroga de un lado con heredad de Santín de Campos de Vila y por el otro lado con el arroyo nombrado de Redinin.

$5^{a}$ La heredad llamada de Redinin de dos ferrados y medio en semiente la que demarca por arriba y abajo con caminos que giran a la herrería de Quinta de un lado con dicho arroyo de Redinin y por el otro con camino transversal.

\footnotetext{
48 1836. Clero regular. Inventarios de bienes existentes en las casas herrerías de: Copia del inventario original..., en AHPL, legajo 241, sign. 18 444, sin foliar.
} 
$6^{a}$ Ítem dos ferrados semiente de tierra labrada junto al molino de la Rotea que demarca por todas partes con heredad y soto de los herederos de D. Álvaro Orozco de Ayán.

$7^{a}$ El prado que llaman do Estreito del otro lado del arroyo de Redinin de dos ferrados en semiente el que demarca por toda partes con heredades de los herederos del dicho D. Álvaro Orozco.

$8^{a}$ El soto de la Rotea que está en medio del Prado de los herederos del referido D. Álvaro, su sembradura tres ferrados.

$9^{a}$ Ítem donde llaman el "Soto da Cancela" o Campos de Vía medio ferrado semiente de tierra, que se halla en medio de sotos de los herederos del expresado Orozco.

10 Dos castañales con su territorio que están dentro del cerrado que quedó de Miguel Rodríguez.

11 Otros dos castañales con su territorio que se hallan al subir de la casa que quedó de dicho Miguel por cima del camino de Carro. 12 Un soto debajo de las casas de Vilameá, que llaman el soto de medias, de cuatro ferrados en semiente, demarca por tres lados con más soto de los herederos de D. José Ángel de Lamela, y por otro con más de D. Bernardo Neira y los de Santín de Campos de Vila.

13 Otro soto donde llaman soto de medias de dos ferrados semiente demarca por arriba con el cerrado de Gayo, por abajo con más soto de los herederos de D. Bernardo de Neira, de un lado con más de los de D. Diego Quiroga de San Martín, y del otro con más que quedó de Miguel Rodríguez del Puente.

14 Otro soto de un ferrado semiente sobre el lugar de Vilameá, demarca por dos lados con más soto de los herederos de D. Antonio Somoza del Hospital, y por las demás partes con heredad de los herederos de Rodrigo de Fisteus.

15 Otro soto al nombramiento de Armenteiro de veinte ferrados semiente demarca por abajo y dos lados con propiedad de los herederos de dicho D. Diego de San Martín y por la parte de arriba con más soto de José Fernández y herederos del mencionado Rodrigo de Fisteus.

16 Otro soto al nombramiento das Fontelas, su cabida de un ferrado semiente, demarca por arriba y un lado con heredades del dicho Rodrigo de Fisteus y por abajo con el camino que va de este nombre para la Lamas.

17 Otro soto de un ferrado semiente, sito en cima de la cortiña que está sobre el Iglesario de Fisteus, con el cual demarca. 
18 El soto llamado do Fial con porción de monte junto a él, su sembradura treinta ferrados semiente poco más o menos demarca por abajo con el arroyo que baja de las Forcadiñas a Redinin y por arriba con el camino que va del lugar de Campos de Vila para dichas Forcadiñas.

19 Un prado con una huerta a su cabecera todo en una finca; su sembradura veinte ferrados semiente poco más o menos demarca por el oriente con la Acequia de la herrería; norte con la Chapacuña de la misma; mediodía con la fábrica, y poniente con el Río de Quiroga.

20 Una villa al oriente de la casa de habitación de la Herrería cerrada sobre sí su cabida diez cavaduras.

21 Y por último se reconoció dos ferrados semiente de tierra labradía al nombramiento do Bal que por ser bien conocida se omiten sus demarcaciones.

Cuyas fincas arriba expresadas se hallan sitas en este término de la parroquia de San Tomé de Fisteus de la Jurisdicción de Quiroga ${ }^{49}$.

$\mathrm{Al}$ igual que en el caso de la herrería de Rugando, el inventario de A Rodela no acabó en la relación de los predios rústicos. Seguidamente, se pasó a señalar las rentas que percibía el administrador de la herrería en concepto de paga por diferentes lugares: veintiocho ferrados de centeno y ocho de castañas secas de Álvarez da Lama por el lugar de San Cristóbal, dos ferrados de centeno de Bernardo Mondelo por el foral de Lama y cincuenta y cinco reales y medio de Pedro Núñez y consortes por el foral de Campo do Bal.

Una vez citadas las rentas que percibía la herrería de A Rodela, se hizo referencia a los pagos que, a su vez, esta hacía por distintos motivos. El cabezalero de la encomienda de Quiroga, un tal Ildefonso Flórez, recibía de la herrería de A Rodela "treinta cuartillos de vino; medio ferrado de centeno; la sexta parte de un ferrado de trigo y cuatro reales y medio en dinero" ${ }^{\circ}$. A Francisco Rodríguez, también cabezalero de la encomienda de Quiroga, le pagaban cinco ferrados de centeno y dos de trigo. Finalmente, el conde de Maceda recibía "cuatrocientos reales anuales por la vena que se conduce de la venera de Formigueiros para el consumo de esta Herrería"51, es decir, el doble de lo que pagaba la herrería de Rugando.

\footnotetext{
49 1836. Clero regular. Inventarios de bienes existentes en las casas herrerias de: Copia del inventario original..., en AHPL, legajo 241, sign. 18 444, sin foliar.

50 1836. Clero regular. Inventarios de bienes existentes en las casas herrerías de: Copia del inventario original..., en AHPL, legajo 241, sign. 18 444, sin foliar.

51 1836. Clero regular. Inventarios de bienes existentes en las casas herrerías de: Copia del inventario original..., en AHPL, legajo 241, sign. 18 444, sin foliar.
} 
En el momento de la realización del inventario, además de las fincas rústicas y urbanas, en la herrería de A Rodela había una serie de bienes muebles que también fueron inventariados. Eran los siguientes:

Existen en dicha casa de habitación para servicio de ella cuatro mesas dos de ellas con sus cajones de buen servicio, y las otras dos deterioradas.

Cuatro arcas la una de un servicio regular y las otras deterioradas.

Una artesa de amasar pan bastante usada.

Dos bancos de respaldos a medio uso.

Tres medios catres usados, el uno de ellos desarmado y sin cuerda.

Dos tarimas viejas.

Un baño de una pieza para salar carne a medio uso.

Dos escarpias de hierro para colgar aquella.

Dos cubas la mejor con dos arcos de hierro.

Dos cubetos más viejos de un regular servicio.

Unas balanzas de hierro con tres pesas de lo mismo, la una de dos libras y las otras de a libra cada una.

Una romana grande con su pesa de hierro.

Un cuadro con la imagen de Cristo.

Una estampa con cañas, de la imagen de Santo Domingo.

Un estante para libros.

Unas balanzas grandes de hierro para pesarlo con sus pesas de lo mismo, que son siete, a saber: de un quintal, de dos libras, tres, cuatro, seis y siete, y además hay otras dos de medio quintal cada una.

Un [morillo] de hierro para la cocina.

Un banco de id.

Dos mesas de asiento.

Una escalera de mano.

Una banquito pequeño, con su barcal para despachar vino en la despensa.

Otros dos bancales para la bodega.

Una cántara de barro de medio cañado.

Otras tres nuevas y pequeñas.

Un ferrado de hierro, marcado de esta Jurisdicción.

Una amboa de barro pequeña.

Una medida en una pieza, que hace maquila y media ${ }^{52}$.

\footnotetext{
52 1836. Clero regular. Inventarios de bienes existentes en las casas herrerias de: Copia del inventario original..., en AHPL, legajo 241, sign. 18 444, sin foliar.
} 
Los enseres anteriores se completaban con las herramientas que había en el interior de la fábrica para el trabajo del hierro, que también fueron inventariadas, al igual que los bienes muebles existentes dentro de la capilla de la herrería:

La palanca mayor.

Dos balanzas de las aguas.

Otras dos de fundir.

Dos tenazas de caldear.

Otra de repillar.

Otra tenaza para componer la talladera y más herramienta menor.

Una suara.

Un rodo, de sacar el carbón todo de hierro.

Dos tornos de componer el mazo y yunque.

Unas tenazas de gaviar las piezas.

Un torna carbón.

Dos tenazas Patelas.

Una tenaza, menos corveta.

Otra llana.

Una [...]

Un garrote para enderezar el hierro.

Una pala.

Un espeto, para limpiar la tubera.

Un rodo viejo.

Dos cuartillos para la vena.

Una talladera para las agoas.

Otra de picar el hierro.

Dos [...]

Un cuartillo de Gallas.

Un $[\ldots]$

Dos cañones viejos y sobrantes para los fuelles.

Dos picachos; cuyas herramientas se hallan corrientes de peso todas ellas siete quintales.

El árbol y rueda de maciar lo mismo.

El mazo y yunque corriente.

El bancado casi del todo nuevo.

Toda la fábrica y carbonera cubierta de madera y losa, con su puerta cerradura y llave.

También tiene la carbonera otras dos puertas con cerraduras y llaves.

La fragua rodeada de aguas perdidas y yunques viejos. 
La compuerta que se halla junto a la tapacuña nueva y las demás bastante deterioradas.

Siguen los enseres pertenecientes a la capilla que hay en la casa de habitación y se componen de una mesa de altar, encima del cual se halla un cristo dorado en partes con la estatua de Nuestra Señora del Rosario, y al lado derecho la de San Benito, y a su izquierdo la de San Cristóbal, y en el medio un crucifijo tiene para su servicio un mantel para el altar, atril y misal todo viejo = un Caliz de plata con su patena y cucharilla que todo pesa treinta onzas = un amito, alba y cingulo = tres casullas, morada, verde y encarnada = una bolsa de corporales sitos y paño de cáliz = otra estola verde, manipulo y paño de cáliz.

Únicos efectos que fueron hallados en dicha Casa Herrería ${ }^{53}$.

Al igual que en el caso de la herrería de Rugando, de la herrería de A Rodela se conserva otro documento vinculado al proceso desamortizador. Se trata de la "Relación que manifiesta las fincas rústicas y urbanas pertenecientes a la Herrería de Rodela dependiente del extinguido monasterio de Samos para que con presencia del pliego de condiciones adjunto se proceda a su arrendamiento en el presente año de $1837^{\prime \prime 54}$. De nuevo, nos encontramos ante una relación de las fincas y construcciones que se pretendía arrendar, que se enumeraron y describieron de la misma forma que en el inventario de principios de 1836. Sin embargo, las propiedades relacionadas no eran todas las que formaran parte en el pasado de esta herrería del monasterio de Samos y quedaron fuera de la relación tanto el primer bien urbano del inventario de 1836, como las fincas rústicas número 17 , $18,19,20$ y 21 .

El siguiente paso dado fue la venta de esta propiedad, de lo que tenemos constancia documental en otro legajo conservado de la desamortización. Los nuevos dueños pagaron por ella 620500 reales en $1839^{55}$. Además sabemos que siguió funcionando como herrería hasta finales del siglo XIX, aunque no de forma continua ${ }^{56}$.

\footnotetext{
53 1836. Clero regular. Inventarios de bienes existentes en las casas herrerías de: Copia del inventario original..., en AHPL, legajo 241, sign. 18 444, sin foliar.

54 1836. Clero regular. Inventarios de bienes existentes en las casas herrerías de: Copia del inventario original..., en AHPL, legajo 241, sign. 18 444, sin foliar.

55 Libro de registros de los Benedictinos de Samos y Lorenzana (1838...), en AHPL, legajo 10, sign. 18 212, sin foliar. GonzÁLEz PéREZ, A producción tradicional..., pág. 204.

${ }^{56}$ Estadística Minera correspondiente al año de 1874 [en línea], Madrid, Dirección General de Estadística, Agricultura, Industria y Comercio, 1879, págs. 48-49, disponible en: < http://info.igme.es/estminera/ default.aspx > [Consulta: 20/6/2017]. Estadística Minera correspondiente al año de 1876 [en línea], Madrid, Dirección General de Estadística, Agricultura, Industria y Comercio, 1881, pág. 60, disponible en:
} 


\section{Conclusiones}

Para terminar este trabajo se puede afirmar que es posible realizar un conocimiento de la realidad pasada de las herrerías monásticas a través del análisis de los inventarios que se redactaron como consecuencia del proceso de secularización experimentado por el monasterio de San Julián de Samos, en los años treinta del siglo XIX. Estos documentos contienen una gran cantidad de datos sobre el número, el tipo y las características, entre otros, de las construcciones que formaban parte de las antiguas herrerías, así como de todas aquellas fincas agrícolas que las rodeaban y de las que se servían.

Los inventarios se ejecutaron con el objetivo inicial de conocer los bienes expropiados para tasarlos correctamente antes de su subasta pública. Es precisamente ahí donde se encuentra la clave para que hoy los inventarios sean fuentes documentales históricas de gran relevancia, pues de forma escrita, nos dan acceso al conocimiento de la materialidad de algunos de los viejos espacios monásticos. En definitiva, a través de sus páginas es posible la reconstrucción de un periodo concreto de la historia de estas herrerías, el más reciente, pero no por ello más conocido y, sobre todo, la información que contienen estos documentos nos permite acercarnos a una parte de un inmenso patrimonio monacal que, en la actualidad y por diversos acontecimientos históricos, se encuentra, en muchos casos, abandonado, perdido u olvidado.

\section{BIBLIOGRAFÍA}

Arias Arias, Plácido, Historia del Real Monasterio de Samos, Santiago de Compostela, Imprenta, Lib. y Enc. Seminario Conciliar, 1950.

Arias Cuenllas, Maximino, Historia del monasterio de San Julián de Samos, Samos, Monasterio de Samos; Diputación Provincial de Lugo, 1992.

Estadística Minera correspondiente al año de 1874 [en línea], Madrid, Dirección General de Estadística, Agricultura, Industria y Comercio, 1879, disponible en: $<$ http://info.igme.es/ estminera/default.aspx> [Consulta: 20/6/2017].

Estadística Minera correspondiente al año de 1876 [en línea], Madrid, Dirección General de Estadística, Agricultura, Industria y Comercio, 1881, disponible en: <http://info.igme.es/ estminera/default.aspx> [Consulta: 20/6/2017].

Folgar de la Calle, M. a del Carmen y Goy Diz, Ana E. (dirs.), San Xulián de Samos: Historia e arte nun mosteiro. Opus Monasticorum III, Santiago de Compostela, Xunta de Galicia, 2008.

Gaceta de Madrid [en línea], núm. 211, págs. 841-842, disponible en: <www.boe.es/buscar/ gazeta.php> [Consulta: 25/6/2017].

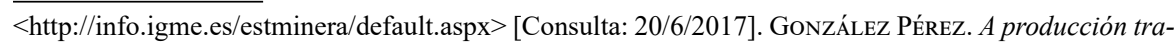
dicional..., pág. 204. GuItIÁN Rivera. "La destrucción histórica del...”, págs. 141-142. 
González Pérez, Clodio, "La producción tradicional de hierro en la provincia de Lugo: las ferrerías", Narria, 63-64 (1993), págs. 30-35.

González Pérez, Clodio, A producción tradicional do ferro en Galicia: as grandes ferrerías da provincia de Lugo, Lugo, Deputación Provincial de Lugo, 1994.

Guitián Rivera, Luis, "La destrucción histórica del bosque en Galicia”, Semata Ciencias Sociais e Humanidades, 13 (2001), págs. 105-166. 